\title{
Recommendations of the Polish Society of Gynecologists and Obstetricians regarding caesarean sections
}

\author{
Miroslaw Wielgos ${ }^{1}$, Dorota Bomba-Opon ${ }^{1}$, Grzegorz H. Breborowicz ${ }^{2}$, \\ Krzysztof Czajkowski ${ }^{3}$, Romuald Debski ${ }^{4}$, Bozena Leszczynska-Gorzelak ${ }^{5}$, \\ Przemyslaw Oszukowski ${ }^{6}$, Stanislaw Radowicki ${ }^{7}$, Mariusz Zimmer ${ }^{8}$ \\ ${ }^{1} 7^{\text {st }}$ Chair and Department of Obstetrics and Gynecology, Medical University of Warsaw, Poland \\ ${ }^{2}$ Chair of Perinatology and Gynecology, Department of Perinatology and Gynecology, Karol Marcinkowski University of Medical \\ Sciences, Poland \\ ${ }^{3} 2^{\text {nd }}$ Chair and Department of Obstetrics and Gynecology, Medical University of Warsaw, Poland \\ ${ }^{4}$ Department of Obstetrics and Gynecology, Centre of Postgraduate Medical Education, Poland \\ ${ }^{5}$ Department of Obstetrics and Perinatology, Medical University of Lublin, Poland \\ ${ }^{6}$ Department of Obstetrics and Gynecology, Medical University of Lodz, Poland \\ ${ }^{7}$ Medical University of Warsaw, Poland \\ ${ }^{8} 2^{\text {nd }}$ Chair and Department of Obstetrics and Gynecology, Medical University of Wroclaw, Poland
}

The epidemiology and consequences of delivery by caesarean section for mother and child

In recent years, the worldwide percentage of deliveries by caesarean section has increased. However, this has only improved obstetric outcomes in low-income countries [1, 2]. Unfortunately, in Poland and other high-income countries, the rate of caesarean section, which is greater than $20 \%$, is no longer associated with decreases in the perinatal mortality of mothers and their offspring. Currently in Poland, $43.85 \%$ of births are by caesarean section [3]. The increased number of caesarean sections may be associated with the development of perinatal medicine, and of diagnostics in particular, which can have an impact on the frequency of detecting foetal abnormalities. The results of randomised multicentre study carried out across various populations in the last two decades have indicated there is a greater risk to a child during vaginal delivery in cases of breech presentation [4]. Also, among women with one prior caesarean, planned elective caesarean section compared with planned vaginal birth was associated with a lower risk of fetal and infant death or serious infant outcome [5]. As a consequently, some national associations of obstetricians and gynecologists recommended the classification of pregnant women with these abnormalities for elective caesarean section. Epidemiological data from various populations indicate, however, that the main indications for caesarean section are still labour arrest and intrapartum fetal hypoxia [6, 7].

The development of anaesthesiology and the widespread use of ductal anaesthesia for caesarean sections have both significantly reduced maternal mortality. However, compared with vaginal birth, a caesarean section still carries a ten-fold higher risk of labour haemorrhage and thromboembolic complications, which are the leading causes of death in women related to delivery $[8,9]$. Studies of the long-term effects have shown there is an increased risk of abnormal placental implantation, such as placenta praevia or placenta accrete, with each subsequent caesarean section [10]. The number of laparotomies associated with caesarean sections also increase the risk of surgical complications during other surgical interventions in the abdominal cavity.

Recent scientific reports also indicate that delivery by caesarean section has negative effects for the child. Breathing disorders are more common in fetuses, even among those born before the end of the 39th week of pregnancy [11]. Caesarean delivery also has lifelong consequences associated with the colonisation of the newborn by the mother's 
skin flora rather than by the flora of the genital tract [12]. Epidemiological studies indicate that children born by caesarean section have an increased risk of developing disorders in the immune system, and are more likely to have allergies, asthma and type 1 diabetes $[13,14]$.

Considering the negative consequences of caesarean sections for both mother and child, every effort should be made to reduce the percentage of caesarean sections, particularly among healthy primiparous women with uncomplicated pregnancies. The aim of the recommendations below is to determine, based on available research results, the optimum indications for caesarean delivery. It is also noted that, before a caesarean section can proceed, a pregnant woman must provide her informed consent.

\section{INDICATIONS FOR A CAESAREAN SECTION:}

\section{Indications for an intrapartum caesarean section} -arrested labour

Classic studies from the 1970s indicated that active cervical dilation occurs after reaching $4 \mathrm{~cm}$ [15]. A comparison of the lengths of spontaneous labour over the last 50 years has shown a significant extension of the first stage by an average of 2.6 hours in primiparous women and by two hours in multiparas [16]. This is related to, among others, more frequent use of labour induction and stimulation, as well as of epidural anaesthesia. The results of a retrospective study of over 62,000 spontaneously initiated and physiological deliveries between 2002 and 2008, conducted as part of the Consortium on Safe Labour project, indicated that the time needed to change the cervical dilation from 4 to $5 \mathrm{~cm}$ was up to six hours (95th percentile) and from 5 to $6 \mathrm{~cm}$ was three hours (95th percentile). Parity did not significantly affect the results obtained. Data analysis showed that the acceleration phase in active labour may not begin until $6 \mathrm{~cm}$ dilation (median: $1 \mathrm{~cm}$ about every $30 \mathrm{~min}$ ) [16]. It should be noted that oxytocin augmentation was used in half of the patients and epidural anaesthesia in $80 \%$ of the women undergoing the study.

Considering the results of research carried out in recent years, arrest of the first stage of labour should be recognised if at least $6 \mathrm{~cm}$ cervical dilation does not progress further during at least four hours of observation.

Along with the process of cervical dilation during delivery, the fetus's presenting part descends to the birth canal. The median time for the fetal head to descend in relation to the interspinal line (on a scale from -3 to +3 ), to reach the next degree is under two hours, and less than one hour after crossing point 0 [17]. During active labour $(>6 \mathrm{~cm}$ dilation), the median is the interspinal line. The descent of the fetus's presenting part took longer in primiparous women, and in cases of induced and stimulated births. The process of descent and rotation of the fetal head in the birth canal determines the length of the second period of delivery. However, the timing of second stage pushing efforts (whether immediate or delay) did not affect the rate of spontaneous vaginal delivery [18]. The use of epidural anaesthesia may prolong the second stage of labour and increase the risk of operative vaginal delivery [19]. However, it was found that the use of anaesthesia before the active dilation phase $(<4 \mathrm{~cm})$ had no impact on the percentage of operative deliveries [20].

Different dynamics and slower progress than those reported above were recorded in cases of induced labour in both primiparous and multiparous women [21]. In retrospective studies of induced labour, in which dilation at $4 \mathrm{~cm}$ was the criterion indicating the active phase of labour, it was found that a prolonged latent phase was associated with higher percentages of caesarean delivery, and greater risks of haemorrhage and of amniotic inflammation [22, 23]. However, another study also suggests that continuation of the latent phase of labor for longer than 12 hours may provide patients with a reasonable chance of a vaginal delivery without the frequent occurrence of untoward health outcomes [23]. The cohort of women in that study continued to achieve a vaginal delivery in the majority of cases until 18 hours had passed without entering the active phase of labor. Even after 18 hours of latent labor, a vaginal delivery was achieved in $32 \%$ of the cases.

Given the higher risk of complications during prolonged labour, sound medical reasons are the justification for labour to be induced [24]. In order to increase the efficiency of inductions and shorten delivery times, pre-induction with prostaglandins or by mechanical methods should be considered [24]. If proper uterine contractile activity is not obtained, reclassification and postponement of the induction should be considered.

\section{Recommendations:}

$\checkmark$ Caesarean section should be performed if cervical dilation of a minimum of $6 \mathrm{~cm}$ has not progressed during a minimum of four hours of observation during the active phase of the first stage of labour (Category C).

$\checkmark$ Caesarean section should be performed if the fetal head does not descend or rotate for up to two hours during the second stage of labour, or up to three hours if edpidural anaesthesia has been administered (Category C).

$\checkmark$ In the case of an unsuccessful labour induction, and if the active phase of labour has not been achieved, despite the stimulation of contractile activity for more than 18 hours (a minimum of $6 \mathrm{~cm}$ dilation), re-qualification should be undertaken to consider the postponement of induction or performance of caesarean section. Repeated ineffective labour induction is an indication for caesarean section (Category C). 


\section{Indications for an intrapartum caesarean section - intrauterine fetal hypoxia}

Life-threatening fetal destress can be cause by umbilical cord prolapse, premature separation of the placenta, or rupture of the uterus. An abnormal fetal heart rate pattern is one of the most common indications for caesarean section during delivery. Abnormal cardiotocography tracings characterised by persistent bradycardia $(<110$ beats per minute), or the loss of baseline fetal heart rate variability with recurrent late decelerations or sinusoidal patterns are both associated with the occurrence of acidosis and may lead to encephalopathy and cerebral palsy $[25,26]$. Resuscitation should then be undertaken, during which the position of the mother should be changed, the oxygen proportion of the air that she inhales should be increased, and hypotension and excessive uterine contractions should be stopped and reversed. The only possible assessment method that can exclude foetal acidosis is the analysis of capillary blood collected from the fetal scalp; however, this method is not widely recommended because of its invasiveness. An abnormal fetal heart rate pattern may be the result of rapid cervical dilation, tachysystole ( $>5$ contractions/ 10 minutes or contraction $>2$ minutes, abnormal relaxation), or hypotension associated with epidural anaesthesia during delivery. Differential diagnosis should take account of the possibility of a premature separation of the placenta or uterine rupture.

\section{Recommendations:}

$\checkmark$ Delivery should be completed immediately by caesarean section in cases of (Category $\mathrm{D}$ ):

- umbilical cord prolapse,

- suspected separation of the placenta,

- suspected uterine rupture.

$\checkmark$ Delivery should be completed by caesarean section in the case of an abnormal CTG record that persists despite the use of methods to improve the intrauterine wellbeing of the fetus and when immediately vaginal delivery is not possible (Category $\mathrm{D}$ ).

\section{Non-cephalic fetal presentation}

About $3-4 \%$ of fetuses are in breech presentation at term. The results of a randomised multicentre and prospective study conducted in the 1990s, including several centres in Poland, clearly indicated that spontaneous delivery in the case of a breech presentation is associated with an increased risk of child mortality and morbidity [4]. At the same time, in a meta-analysis of various retrospective studies, there were no significant differences found in maternal complications when comparing spontaneous vaginal delivery and planned caesarean section. In over $90 \%$ of cases, births were conducted by experienced obstetricians. The incidence of fetal and neonatal complications was not affected by the mother's age and parity, gestational age, fetus size and the spontaneous initiation of labour. A planned caesarean section in the case of a breech presentation improved the obstetric outcomes, especially in countries with low perinatal mortality $[27,28]$. Numerous retrospective studies of various populations confirm the results obtained [29]. However, there are no data indicating the advantage of caesarean section over spontaneous deliveries in cases of breech presentation diagnosed during an advanced stage of labour. A caesarean may pose a greater risk of injury to a fetus in breech, particularly during the second stage of labour in multiparous women.

The results of a multicentre randomised trial Twin Birth Study and of retrospective cohort studies indicate that in twin pregnancies, delivery of the second fetus in a breech presentation does not significantly increase the risk of fetal complications [30, 31].

Similarly, cohort studies of foetal deliveries before the 26th week of gestation do not indicate that caesarean sections significantly improve the survival of newborns [32, 33]. Caesarean sections in pregnancies before 26 weeks have been shown to be a risk factor for complications in subsequent pregnancies. Considering the risk to a mother's health of caesarean delivery, spontaneous delivery seems to be reasonable in cases of breech presentation with prenatally diagnosed lethal defects.

The transverse lie position of a fetus during delivery is associated with a threat to the life of both the fetus and the mother and is an absolute indication for caesarean section.

In the case of the non-cephalic fetus presentation at term before the onset of labour, an attempted external cephalic version (ECV), is an alternative to caesarean delivery. A meta-analysis of eight randomised trials involving 1,388 women showed that ECV reduced the risk of breech position during labour, increased the chances of spontaneous deliveries and reduced the number of caesarean deliveries. [34]. External cephalic version did not significantly affect the neonatal outcome.

\section{Recommendations:}

$\checkmark$ Caesarean section should be performed in the case of a transverse lie position presentation of a live fetus (Category D).

$\checkmark$ Caesarean section should be performed in the case of a breech presentation of a live fetus (Category A), except in the following cases, in which vaginal labour can be considered:

- twin pregnancy with the second fetus in breech position fetus (Category A),

- spontaneous preterm delivery before the 25 th week of gestation (Category C),

- lethal fetal defects (Category D), or 
- diagnosis of breech position at an advanced stage of labour (Category D).

$\checkmark$ In the case of a non-cephalic presentation of the fetus after the 37th week of gestation, in a single pregnancy, an attempted external cephalic version can be suggested to a pregnant woman (Category B).

\section{Multiple pregnancy}

\section{Delivery of more than two fetuses}

After the 25th week of gestation, pregnancy with more than two fetuses is an indication for caesarean section. Spontaneous delivery is permissible in the case of the spontaneous onset of premature labour before the 25th week.

\section{Twin delivery}

Twin delivery is currently one of the greatest challenges for modern obstetrics. Retrospective analyses indicate a higher risk of complications in vaginal delivery compared with elective caesarean delivery [35]. However, this indication is not confirmed by the recently published results of the multicentre randomised trial Twin Birth Study [30]. The 2013 study comprised 2,804 women with twin pregnancies who were between 32 and 39 weeks of gestation, and with whom the first fetus was in a cephalic presentation. There were no statistically significant differences in birth and neonatal complications between the study groups. All the deliveries took place in specialised centres providing intrapartum fetal monitoring and the possibility of immediate delivery by caesarean section. This Twin Birth Study showed that when proper care is provided, vaginal delivery in a twin pregnancy with the first fetus in a cephalic presentation is as safe as delivery by caesarean section.

Currently, there are three absolute indications for caesarean section in a twin pregnancy: monoamniotic pregnancy, conjoined twins and non-vertex position of the first fetus [36]. In a breech presentation of the first fetus, fetuses may collide. Although this complication is extremely rare, it is associated with a $30-40 \%$ risk of fetal death [36]. However, a breech presentation of the second fetus is not a contraindication for vaginal delivery. In the antenatal period, it is difficult to clearly determine the location of the second fetus because in $20 \%$ of cases the position of the second fetus changes after the birth of the first twin [36]. In the Twin Birth Study, over $30 \%$ of the vaginal deliveries took place with a breech presentation of the second fetus [30]. In a small percentage of cases, external cephalic version was attempted, with a $42 \%$ success rate. Much better results were obtained by assisted vaginal breech delivery (95\% were effective) [30]. The results of retrospective cohort studies of twin pregnancies indicate that there is a higher percentage of vaginal deliveries with breech presentation of the second fetus at the onset of labour compared with those where the second fetus changed from a cephalic to a breech presentation during delivery ( $89 \%$ to $56 \%$ ). In a meta-analysis of various retrospective studies, labour induction was shown to be one of the factors that increased the chance of vaginal delivery.

It is very important to monitor and manage the delivery of the second fetus in a vaginal twin delivery. Due to the effort of labour, maternal tachycardia may be misinterpreted as the heart rate of the fetus which is still in the uterus. It is advisable to confirm the presence of the fetal heart rate, preferably by an ultrasound examination. Research indicates that there is a very low risk (4-5\%) of caesarean delivery for the second fetus after a spontaneous birth of the first child [36]. The second fetus should be delivered by caesarean section in the event of umbilical cord prolapse or premature separation of the placenta. External cephalic version can be attempted if the second fetus is in the transverse position before the amniotic fluid has leaked out. Conversely, the transverse position of the second fetus after the amniotic fluid has leaked out is an indication for caesarean section. Diagnosing bradycardia in the second fetus after the delivery of the first twin requires interventions aimed at the immediate delivery of the second fetus.

Additional factors should also be considered in the qualification of a pregnant woman in a twin pregnancy for delivery. In a monochorionic diamniotic pregnancy, due to vascular placenta anastomosis, a twin-to-twin transfusion syndrome (TTTS) may occur during labour. A monochorionic diamniotic pregnancy is thus a relative indication for caesarean section, particularly if TTTS is diagnosed during pregnancy or the difference in estimated fetal weights exceeds $20 \%$. The presence of a caesarean section scar is also assumed to be a relative indication for caesarean section. Caesarean delivery of a twin pregnancy is also recommended if there are other obstetric indications, of the type are not only typical of multiple pregnancies.

\section{Recommendations:}

$\checkmark$ Caesarean section should be performed in pregnancy with more than two fetuses after 25 weeks of gestation (Category D).

$\checkmark$ Caesarean section should be performed in the case of conjoined twins (Category D).

$\checkmark$ Caesarean section should be performed in the case of a monochorionic monoamniotic twin pregnancy (Category D).

$\checkmark$ Caesarean section should be performed in a twin pregnancy in the case of a non-cephalic position of the first fetus (Category D).

$\checkmark$ A twin pregnancy with the first fetus in vertex presentation is not an indication for caesarean section (Category A). 
$\checkmark \quad$ In the case of a monochorionic diamniotic twin pregnancy, caesarean section may be considered due to the risk of twin-to-twin transfusion syndrome (TTTS), in particular when the difference between the estimated fetus weights is above $20 \%$, and in cases of TTTS being recognized during pregnancy (Category $\mathrm{D}$ ).

$\checkmark$ In a twin pregnancy, caesarean section may be considered in cases of postoperative uterine scarring (Category D).

$\checkmark$ Caesarean section after spontaneous delivery of the first fetus should be performed in the following cases (Category D):

- umbilical cord prolapse in the second fetus,

- premature separation of the placenta,

- transverse position of the second fetus,

- life threatening symptoms in the second fetus.

$\checkmark$ In the case of a breech presentation of the second fetus, assisted vaginal breech delivery should be performed after delivery of the first twin (Category A).

$\checkmark \quad$ In the case of a transverse position of the second fetus after delivery of the first twin, external cephalic version may be considered when the amniotic fluid has not leaked out (Category C).

\section{Abnormal fetal growth Fetal hypotrophy}

If the fetal weight is too small for gestational age (SGA), identifying the cause of the fetal hypotrophy is of fundamental importance for the choice of the childbirth route. A small fetal weight is not in itself an indication for caesarean section. If SGA is a result of family/genetic causes, the pregnancy should be treated as normal. If intrauterine fetal growth restriction (IUGR) is caused by placental insufficiency (premature aging, hematoma, or partial separation) or by insufficient blood supply to the placental site (hypertension, connective tissue disease, thrombophilia), caesarean section should be chosen, if there are even small signs of fetal hypoxia [37, 38]. In this latter situation, it can be suspected that there is acute hypoxia overlapping with chronic placental insufficiency.

\section{Fetal macrosomia}

Excessive fetal growth is usually considered in two categories:

1. A fetus with a weight above the 90th percentile for gestational age is considered large for gestational age (LGA).

2. Fetal macrosomia occurs when the expected fetus weight exceeds $4000 \mathrm{~g}$ or $4500 \mathrm{~g}$ depending on the source, regardless of gestational age.

Analyses of retrospective cohort studies indicate an increased risk of birth and neonatal complications in cases of fetal weight above $4000 \mathrm{~g}$ [39]. An additional threat to the mother's health was found during births of newborns weighing over $4500 \mathrm{~g}$. Moreover, an abrupt increase in the risk of complications and increased perinatal mortality was noted in cases of fetuses whose birth weight exceeded $5000 \mathrm{~g}$. Unfortunately, both clinical methods and ultrasound measurements are characterised by low sensitivity and specificity in the prediction of fetal macrosomia [40]. The evaluation of various ultrasound parameters in determining the risk of shoulder dystocia in recent years has shown that an ultrasound-estimated fetal weight above $4000 \mathrm{~g}$ and/or the difference between the abdominal diameter and biparietal diameter of greater than $2.6 \mathrm{~cm}$ are both associated with an increased risk of shoulder dystocia. Cohort studies indicate an increased risk of complications in cases of fetal macrosomia particularly in pregnancies complicated by diabetes [41]. Elective caesarean sections in pregnant women with diabetes in cases of an ultrasound-estimated fetal weight above $4250 \mathrm{~g}$ contributed to a reduction in the incidence of shoulder dystocia compared with historical data from the period preceding the intervention.

At the moment, we do not have any results from randomised studies that would assess the effectiveness of an elective caesarean section in reducing the risk of labour complications in cases of an ultrasound-estimated high fetal weight.

Shoulder dystocia may also occur in cases of eutrophic fetuses. The occurrence of shoulder dystocia in the obstetric history is associated with a high risk of recurrence of this complication during the next delivery. Therefore, if the estimated fetal weight is comparable with, or higher, than the previous fetal weight, caesarean delivery should be considered.

Excessive fetal weight is one of the risk factors for uterine rupture during delivery in pregnant women after a previous caesarean delivery and in such cases a caesarean section should again be considered.

\section{Recommendations:}

$\checkmark$ Intrauterine growth restriction (IUGR) in cases of symptoms of placental insufficiency, particularly in preterm pregnancies, is an indication for caesarean delivery (Category $\mathrm{D})$. The timing of the caesarean section should depend on gestational age and the severity of the abnormalities.

$\checkmark$ Fetal hypotrophy without signs of placental insufficiency is not an indication for caesarean section (Category C).

$\checkmark$ An expected fetal weight amounting to or exceeding $4250 \mathrm{~g}$ in pregnant women with diabetes is an indication for delivery by caesarean section (Category C).

$\checkmark$ An expected fetus weight amounting to or exceeding $4500 \mathrm{~g}$ is an indication for delivery by caesarean delivery (Category D).

$\checkmark$ A post-caesarean uterine scar with an expected fetal weight amounting to or exceeding $4000 \mathrm{~g}$ is an indication for another caesarean section (Category D). 
$\checkmark \quad$ In the case of shoulder dystocia during a previous delivery, caesarean delivery in the current pregnancy should be considered if the estimated fetal weight is comparable with, or higher, than the previous fetal weight (Category D).

\section{Congenital anomalies}

Most prenatally diagnosed structural developmental anomalies of the fetus, and chromosomal aberrations, are not indications for caesarean section. Lethal structural anomalies and trisomy 13 and 18 should, in fact, constitute a contraindication for caesarean delivery for fetal indications.

Caesarean delivery due to prenatal diagnosed developmental defects in the fetus may be justified in cases where:

1. there is a high improbability of spontaneous delivery;

2. there are reduced chances of successful postnatal treatment because of spontaneous vaginal delivery, including organisational reasons in exceptional cases; or

3. the woman has an unfavourable cervix or there is ineffective induction of labour.

Examples of developmental defects that may constitute an obstacle to delivery are advanced hydrocephalus and large tumours, such as sacrococcygeal teratoma [42]. Vaginal delivery can reduce the chances of successful postnatal treatment in cerebrovascular malformation, myelomeningocele, encephalocele, gastroschisis and omphalocele $[42,43]$. The rationale for caesarean section is the risk of damage to the lesion and contamination by the vaginal flora that increases the risk of infectious complications. Caesarean section should also be performed in pregnancies in which there is a need to intubate the child before closing the fetal-placental circulation (EXIT procedure), e.g., in cases of neck tumours [44].

Prenatal intrauterine correction of fetal defects with the opening of the uterine muscle is an indication for caesarean delivery due to the risk of uterine rupture.

In exceptional cases, the decision to perform a caesarean section in a pregnancy with fetal malformation can be made for organisational reasons. Such cases include conditions in which immediate surgical correction or cardio-surgical intervention may be necessary.

\section{Recommendations:}

$\checkmark$ Caesarean section should be performed in cases of prenatally diagnosed fetal malformation if the abnormality can be a labour obstacle and if spontaneous delivery can reduce the chances of effective postnatal treatment (Category D).

$\checkmark$ Caesarean section should be performed if there is an intrauterine fetal treatment procedure requiring uterine opening (Category D).

$\checkmark$ Fetoscopic surgery is not an indication for caesarean section (Category D).

\section{Preterm delivery}

In the situation of spontaneous preterm labour, the benefits from delivery by caesarean section for the newborn and mother have not been found when the fetus is in vertex position and its weight corresponds to gestational age. Premature caesarean delivery should be performed only at the occurrence of additional indications related to a threat to maternal or fetal life.

A meta-analysis of studies on the impact of the delivery route on the incidence of complications in preterm infants (central nervous system haemorrhage, respiratory distress syndrome, necrotising enterocolitis and septicaemia) did not show beneficial effect for caesarean section [45]. In some of the studies, the mortality rate of neonates born via caesarean section was even twice as high as after vaginal delivery.

However, in cases of prematurely born fetuses with restricted intrauterine growth, a caesarean section increases the chance of survival and reduces morbidity [46]. Studies have also shown that there is also a higher risk of intrapartum hypoxia, umbilical cord prolapse, respiratory disorders and intraventricular haemorrhage in fetuses after a breech presentation vaginal delivery [47].

\section{Recommendations:}

$\checkmark$ Spontaneous preterm labour should be ended by caesarean section in cases of fetal breech presentation in pregnancy after 25 weeks of gestation. (Category A).

$\checkmark$ Symptoms of fetal asphyxia during spontaneous preterm labour should be an indication for caesarean section in pregnancy after 25 weeks of gestation (Category C).

\section{Abnormal placental implantation}

Abnormal placental implantation is recognised when the villi of the placenta attach to the uterine muscle; in extreme situations, they can invade into the peritoneum or bladder wall. Abnormal placental implantation may apply to all its locations in the uterine cavity (most often in the lower segment in patients with a history of caesarean section) [48]. The three types differ according to the depth of the penetration of the villi:

- placenta accreta, where the villi penetrate the decidua basalis;

- placenta increta, where the villi penetrate the uterine muscle; and

- placenta percreta where the villi penetrate the neighbouring organs (usually the peritoneum and/or the bladder).

In clinical diagnostics, abnormal placental implantation is diagnosed using the imaging techniques of ultrasonography (USG), Doppler examination, and magnetic resonance imaging (MRI); and suspected placenta percreta is detected using cystoscopy [49]. While USG is the basic examination, 
MRI provides additional information if the placenta is attached to the back wall of the uterus. A final diagnosis can be obtained through histopathological examination (after hysterectomy or after removal of a part of the uterine muscle).

The optimal period for delivery in pregnancies that are complicated by abnormal placental implantation is from the 34th to the 37th week of gestation because delivery at this time significantly reduces the risk of haemorrhage [50]. The decision about when to end the pregnancy should be taken by considering the general condition of the pregnant woman. Pregnancy should be completed with an elective caesarean section as this allows measures to be taken to reduce the risk for the mother and fetus. In their study, Silvera et al. showed that the risk of fetal immaturity (after proper respiratory system preparation) is relatively small after the 34th week of gestation, while the risk of heavy haemorrhage increases significantly after the 36th week of gestation [51].

Suspected placenta accreta that has been confirmed intraoperatively is an indication for caesarean hysterectomy [52]. In specialised maternity centres, this conservative procedure is permitted in cases where patients wish to maintain the possibility of further reproduction $[53,54]$. The procedure involves a caesarean section with the unseparated placenta being left in the uterine cavity. Subsequently, the placenta is usually delivered after a few weeks or months. The decision for this conservative treatment should be taken upon discussions with the patient who intends to maintain the possibility of further reproduction (for such reasons as the lack of a child, or uncertainty about the fate of the newborn baby from the current pregnancy), and if her health condition allows this option. The available literature suggests that the chance of maintaining the uterus varies between 40 and $60 \%$, provided that a pregnant woman is properly assessed and prepared for this type of procedure.

\section{Recommendations:}

$\checkmark$ Abnormal placement of the placenta-placenta praevia is an indication for caesarean section (Category D).

$\checkmark$ Suspected abnormal placental implantation in the form of placenta accreta may be an indication for caesarean hysterectomy (Category D).

$\checkmark$ In selected cases of extensive invasion of the uterine muscle by the placenta villi, if the patient wants to preserve the possibility of reproduction, caesarean section and the subsequent leaving of the unseparated placenta in the uterine cavity may be considered (Category C).

\section{Danger to a mother's health and life Sudden cardiac arrest}

Epidemiological data from the United States shows that sudden cardiac arrest was observed in 1:12,000 cases of pregnant women admitted for delivery [55]. Unfortunately, due to changes in the circulatory system during pregnancy, haemodynamic disorders associated with cardiac arrest progress quickly, and resuscitation is difficult. The biggest problem is the pressure on the aorta and the inferior vena cava by the enlarged uterus. A left-lateral tilt position reduces the effectiveness of heart massage. In a statement published in 2015, the American Heart Association recommended the use of manual uterine displacement to the left side during the resuscitation of pregnant women [55]. In an advanced pregnancy, however, such treatment is insufficient, and experts recommend immediate caesarean delivery if the uterine bottom reaches the navel or above. Emptying the uterus increases the possibility of resuscitation. The US review of all the descriptions of caesarean sections performed after sudden cardiac arrest, published prior to 2010 , shows that 19 out of 60 women (31.7\%) survived and in no case did the procedure worsen the prognosis [55].

A caesarean section should be started as soon as five minutes after resuscitation begins in the place where help is provided without moving the pregnant woman. Shortening the time between cardiac arrest in the mother and the extraction of the fetus reduces the risk of neurological damage to the fetus. However, even in a situation where there are no signs of fetal life, a caesarean section should be performed immediately. Due to the urgency of the procedure, it is possible to use minimal asepsis and tools. A midline incision is preferable, but if the operator feels more experienced in a Pfannenstiel incision, this can be performed. The uterus and the abdominal wall should be stitched in a typical manner. If the woman's circulation is restored, using antibiotics and oxytocin should be considered after the caesarean section. When using oxytocin, special care should be taken as it may contribute to another cardiac arrest.

\section{Pre-eclampsia}

Delivery is the only effective way to treat pre-eclampsia. After the 37th week of gestation, the decision to deliver should be made regardless of the severity of pre-eclampsia; and before the 37th week of pregnancy, the decision depends on the condition of the pregnant woman and the fetus. After the 34th week of gestation, it is possible to induce labour, while ensuring intensive supervision of the mother and fetus. Induction of labour should not last longer than 4 to 8 hours and if labour fails to progress, caesarean section should be performed. Caesarean delivery should be considered before the 34th week of gestation. While no advantage has been observed for caesarean delivery over induced labour, however, the latter is more often ineffective, particularly before the 28 th week of pregnancy.

\section{Eclampsia}

In the case of eclampsia, it is recommended to end the pregnancy by caesarean section regardless of its severity. 
The exception is that vaginal delivery is possible only if the condition of the mother and fetus is stable and fast delivery is possible.

\section{HELLP}

The HELLP syndrome may have a fulminant course, with unpredictable consequences for both mother and child. Most patients with this diagnosis are eligible for ending the pregnancy immediately after diagnosis. This especially applies to pregnant women after the 34th week of pregnancy, either in a severe general condition, or with signs of fetal distress. There have been no randomised studies comparing vaginal delivery and caesarean section for maternal and fetal outcomes. In most cases, the HELLP syndrome is an indication for caesarean delivery. Attempting vaginal delivery can only be considered in pregnant women after the 34th week of pregnancy, when they are in good general condition, with confirmed fetal wellbeing, and with a favourable cervix.

Caesarean section in patients with HELLP is a high-risk procedure. The strict rules governing this surgical procedure must be remembered. During surgery, the peritoneum should not be closed, palpable liver assessment should be performed, and the tube should be left in the abdominal cavity and in the subcutaneous tissue.

The above-mentioned forms of hypertension that complicate pregnancy are always associated with the risk of premature separation of the placenta. The occurrence of this complication is an indication for immediate delivery by caesarean section.

\section{Recommendations:}

$\checkmark$ Sudden cardiac arrest in a pregnant woman and her resuscitation are an indication for an immediate caesarean section if the bottom of the uterus reaches the navel or above, and also in the case of fetal heart failure (Category D).

$\checkmark$ Eclampsia is an indication for caesarean section unless there are conditions for immediate vaginal delivery (Category D).

$\checkmark$ Premature separation of the placenta is an indication for immediate caesarean delivery unless there are conditions for immediate vaginal delivery (Category D).

\section{Non-obstetric indications for caesarean section}

The percentage of caesarean sections for non-obstetric indications has increased in recent years. Such indications should be determined individually for each pregnant woman by an interdisciplinary team. This should be preceded by an in-depth assessment of the patient's diagnostic and treatment process, both before and during pregnancy. Consultation with a specialist in another area should assess the risk of the vaginal route of delivery, especially the
Valsalva manoeuvre during pushing, and also the safety of epidural anaesthesia. The final decision on the path of delivery should always be taken by an obstetrician based on assessment of the current clinical situation.

\section{Cardiac indications}

Delivery in pregnant women with cardiac diseases should be carried out in such a way as to minimise cardiovascular stress, which can be achieved by applying regional anaesthesia during delivery. Caesarean section in these patients is associated with a greater risk of stress than spontaneous delivery.

Caesarean delivery is therefore only recommended for pregnant women with Marfan syndrome and an aortic root dilatation of $>45 \mathrm{~mm}$, and in cases of advanced cardiac insufficiency (III and IV NYHA grades) [56].

\section{Pulmonary indications}

Pulmonary indications may occur during pregnancy or delivery. They are diagnosed using blood gas analysis and assessment of the degree of respiratory failure manifested by hyperventilation accompanied by hypocapnia, saturation drop and $\mathrm{pH}$ disturbances.

\section{Orthopaedic indications}

Obstetric obstacles caused by pelvic pathology that prevent a vaginal delivery are an indication for caesarean section.

Pregnant women with a history of pelvic trauma belong to a group of patients for whom the method of completing pregnancy requires careful consideration. Recently, orthopaedic surgical techniques have allowed an increasingly better reproduction of pelvic dimensions and shapes. However, caesarean sections should be performed in patients with a postoperative narrowing of the pelvic dimensions.

\section{Neurological indications}

Epilepsy is the most common neurological pathology in pregnancy. By itself, it is not an indication for caesarean section and most women with good disease control can have a vaginal delivery. Only a small number of pregnant women who have recurrent and prolonged seizures during pregnancy and who are at a high risk of developing an epileptic state may be eligible for an elective caesarean section [57].

Cerebral aneurysm diagnosed in a pregnant patient is an indication for caesarean section. The most common complication of this pathology is a subarachnoid haemorrhage $(\mathrm{SAH})$. This is an emergency medical condition requiring immediate neurosurgical and obstetric intervention.

Elective caesarean section is recommended in most patients with primary brain tumours to minimise the risk of increased intracranial pressure (ICP) associated with the 
risk of subsequent intussusception. Decisions should be made on a case-by-case basis considering assessment of the mother's neurological status along with an assessment of the fetal status and gestational age.

\section{Ophthalmic indications}

As diagnostics and treatment progress, the range of indications for caesarean section for ophthalmic reasons has been revised significantly. At present, indications for caesarean section due to a high risk of ocular complications related to childbirth are as follows [58]:

- proliferative diabetic retinopathy,

- myopia with subretinal neovascularisation,

- advanced glaucoma with advanced defects in the field of view,

- advanced or acute keratoconus,

- postoperative conditions of the eyeball,

- sudden ophthalmologic conditions,

- cortical blindness and serous retinal detachment during eclampsia.

\section{Psychiatric indications}

Two groups of determinants of psychiatric indications for caesarean section can be distinguished [59].

The first group of indications concerns pregnant women with a positive history of mental disorders, or pregnant women whose behaviour has changed during pregnancy or in the period directly preceding the delivery as the result of a mental illness. These factors may raise doubts regarding the likely cooperation of these patients during delivery. In the case of severe psychiatric disorders (psychotic disorders, affective disorders, and deep anxiety disorders) delivery by caesarean section may improve the control of labour and prevent the development of perinatal complications resulting from any exacerbation of psychological symptoms in the perinatal period.

The second group of indications concerns the presence of strong anxiety before childbirth (tocophobia), anxiety reflecting the presence of other types of anxiety disorders, or anxiety occurring in the course of depressive disorders. Any pregnant woman reporting symptoms of anxiety before childbirth should be able to discuss all the medical conditions of spontaneous delivery and caesarean section and consult with a mental health specialist. Caesarean section should be considered if a pregnant woman with the symptoms of tocophobia still does not want to deliver spontaneously after completing psychoeducational interventions.

\section{Oncological indications}

The most common cancers diagnosed in pregnant women include breast cancer and cervical cancer (approximately $50 \%$ of all cancers during pregnancy) [60].

\section{Breast cancer}

Most patients diagnosed with breast cancer during pregnancy can have a spontaneous vaginal delivery or delivery following induced labour at term. However, it should be remembered that regardless of the delivery route, childbirth should take place at least 2 to 3 weeks after the last chemotherapy due to the time needed for regeneration of the bone marrow's haematopoietic function [61]. The percentage of caesarean sections is slightly higher in pregnant women with a history of breast cancer. The decision on the operative completion of pregnancy should be made individually for each patient by an interdisciplinary team composed of an obstetrician, a surgical oncologist and an oncologist [61].

\section{Cervical cancer}

The treatment of cervical cancer patients during pregnancy depends on the stage of the cancer, gestational age and the patient's decision. Diagnosis of cancer in the third trimester of pregnancy is an indication for caesarean section followed by standard treatment [62].

\section{Pheochromocytoma}

The diagnosis of this rare adrenal medulla tumour in pregnancy is an indication for caesarean section to minimise catecholamine release during spontaneous labour [63].

\section{Neoplasms of other organs/systems}

The decision on how to complete pregnancy should be made individually for each patient, depending on the clinical stage of the cancer, the patient's condition and gestational age, in cooperation with specialists in the field appropriate for the given cancer [60].

\section{Infectious indications}

\section{Herpes virus (HSV) \\ Primary infection during pregnancy}

Diagnosis of primary HSV infection in the first and second trimester up to $27+6$ weeks of pregnancy is not an indication for an elective caesarean section if delivery occurs more than six weeks after infection. The diagnosis of primary infection in the third trimester after the 28th week of pregnancy is an indication for an elective caesarean section due to a high risk of vertical transmission.

\section{Secondary infection during pregnancy}

Secondary infection in pregnancy is not an indication for an elective caesarean section [64]. However, if changes occur at the time of labour, caesarean delivery can be considered after informing the pregnant woman about the low risk of 
vertical transmission versus the risk of caesarean section and future pregnancies.

\section{Chickenpox virus}

The method of completing pregnancy in a patient with chickenpox should be determined individually, after consultation with a doctor of infectious diseases. It should be remembered that delivery, regardless of the route, should be planned (if possible) within seven days from the diagnosis of infection due to the reduction of the risk of transmission to the newborn and of maternal complications.

\section{Genital warts}

Caesarean section should be performed only in the case of the diagnosis of giant condylomata, which may be an obstacle to delivery.

\section{Human immunodeficiency virus (HIV)}

Elective caesarean section should be performed in patients with a viral load $>=400$ copies of HIV RNA at 36 weeks of gestation [65].

Planned caesarean section should be considered in pregnant women with a viral load of 50-399 copies of HIV RNA at 36 weeks of pregnancy.

Vaginal delivery may be considered in pregnant women with a viral load $<50$ copies of HIV RNA at 36 weeks of pregnancy and in the absence of obstetric complications.

\section{Recommendations:}

$\checkmark$ Non-obstetric indications for caesarean section should be determined individually for each pregnant woman by an interdisciplinary team. The final decision on the path of delivery is always taken by an obstetrician, based on consideration of the current clinical situation (Category D).

\section{Vaginal birth after caesarean section (VBAC)}

In recent years, there has been an increase in the percentage of pregnant women who have had a previous caesarean section. The results of recent studies indicate that there is an increased risk of perinatal complications in women attempting vaginal delivery after previous cesarean section [5]. However vaginal birth after caesarean (VBAC) with success rates between 60 and $80 \%$ is characterised by the smallest risk of complications [66]. Unfortunately, when comparing caesarean sections arising from the necessity to end attempted childbirth with elective caesarean sections, the percentage of complications is significantly higher in the former than in the latter. When planning delivery in a pregnant woman after a previous caesarean section, risk factors for failure and the conditions for spontaneous delivery after caesarean section should be considered.
An elective caesarean section should be considered if the following factors that increase the risk of scar dehiscence are observed in pregnant women after previous caesarean section:

1. suspected fetal macrosomia (estimated foetal weight above $4000 \mathrm{~g}$ ),

2. multiple pregnancy,

3. breech or transverse position of the fetus,

4. previous classic caesarean incision or other transfundal uterine surgery,

5. more than one previous caesarean section,

6. uterine rupture or third- or fourth-degree perineal tear in the obstetric history,

7. caesarean scar defect - documented on USG TV before pregnancy (thickness of the myometrium in the area of the scar $<2 \mathrm{~mm}$ ),

8. placenta praevia or vasa praevia,

9. previous caesarean section before 30 weeks of pregnancy,

10. short time elapsed since previous caesarean section - less than 12 months,

11. previous caesarean section due to a failure to progress,

12. perinatal injury of a child in a previous pregnancy,

13. shoulder dystocia at comparable or higher estimated fetal body weight,

14. lack of spontaneous initiation of delivery after 40 weeks of pregnancy if the pregnant woman does not consent to labour pre-induction and/or induction.

If there are no additional complications of pregnancy, elective caesarean section should be planned:

- in a single pregnancy after 39 weeks of pregnancy,

- in a dichorionic twin pregnancy after 37 weeks of pregnancy,

- in a monochorionic diamniotic twin pregnancy after 36 weeks of pregnancy,

- in a monoamniotic twin pregnancy after 32 weeks of pregnancy,

- in a triplet pregnancy after 32 weeks of pregnancy,

- in cases of previous classic caesarean incision or other transfundal uterine surgery after classic caesarean section after 36 weeks of pregnancy,

- in a pregnant woman after more than two caesarean sections after 36 weeks of pregnancy,

- in a pregnant woman with placenta praevia or vasa praevia after 34 weeks of pregnancy.

Patient consent for vaginal delivery after a previous caesarean section is not required in the case of spontaneous initiation of labour and in the absence of factors increasing the risk of scar dehiscence. Spontaneous delivery after a previous caesarean section, requires increased supervision of the pregnant woman due to the risk of uterine rupture in the post-caesarean scar. Symptoms associated with scar 
Table 1. Symptoms associated with rupture of the uterine scar after a caesarean section

Symptoms associated with rupture of the uterine scar after
a caesarean section
- abnormal CTG record
- acute abdominal pain, also between contractions
- abnormal relaxation of the uterus between contractions
- pain and tension around the scar after a previous
caesarean section
- sudden disappearance of the uterine contractile function
- retraction of the presenting part of the fetus during internal
examination
- uterine bleeding
- haematuria
- pronounced anxiety of the patient
- tachycardia, hypotonia, maternity shock
- changes in the contour of the pregnant woman's belly
- inability to record the fetal heart rate

dehiscence are shown in Table 1. It should be emphasised that the most common early signs of uterine rupture are fetal cardiac abnormalities in cardiotocography, particularly persistent late and variable decelerations and bradycardia. For these reasons, continuous electronic monitoring of the fetal heart rate is mandatory during spontaneous delivery after a previous caesarean section. Post-caesarean scar dehiscence can occur suddenly, without any predicting symptoms. Suspected uterine rupture after a previous caesarean section is an indication for immediate laparotomy.

During delivery, oxytocin can be administered to support contractile function because, in contrast to induced labour, the majority of studies did not show a relationship between the administration of oxytocin and any increased risk of uterine rupture $[67,68]$. The use of oxytocin, however, requires the documentation of indications for its administration.

Epidural anaesthesia can also be performed during labour. The results of recent studies do not indicate that the use of epidural anaesthesia reduces the chance of spontaneous delivery after a previous caesarean delivery [66]. One should not be afraid of the masked symptoms of uterine rupture because, as presented above, the most common manifestation of uterine rupture is fetal heart failure in cardiotocography. However,
Table 2. Postpartum anticoagulant prophylaxis

Long-term postpartum anticoagulant prophylaxis (6-8 weeks)

- use of anticoagulant prophylaxis during pregnancy

- episode of venous thromboembolism

Short-term postpartum anticoagulant prophylaxis (2-7 days)

- delivery by caesarean section

- asymptomatic thrombophilia

$-\mathrm{BMI}>40$

- occurrence of at least two risk factors

- age $>35$ years

- $\mathrm{BMI}>30$

- multiparity $>3$

- elective caesarean section

- large varicose veins

- smoking

- generalised infection

- longer immobilisation or limited mobility

- pre-eclampsia

- extended delivery $>24 \mathrm{~h}$

- postpartum treatments

careful attention must be paid if a pregnant woman with epidural anaesthesia reports intensifying pain and the necessity of an increased dosage of analgesics because this may be an indication of the threat of uterine rupture.

\section{Spontaneous labour pre-induction and} induction after a previous caesarean section

Spontaneous labour pre-induction and induction can be performed in pregnant women after a previous caesarean section that was performed for maternal or foetal indications. However, pregnant women should be informed about the increased risk of uterine rupture and the increased risk of having an urgent caesarean delivery. The smallest, approximately 1.5 -fold, increase in risk occurs when using mechanical methods of labour pre-induction/induction, such as Foley catheter placement [69]. An approximately twofold increase in risk is associated with the use of oxytocin [66]. It has been observed that the risk of uterine rupture is higher when using high doses of oxytocin and therefore this method should be used with caution. The use of prostaglandins is contraindicated because it is associated with the highest (more than three-fold) risk of uterine rupture [70].

Strength of recommendations
Level A - recommendations are based on evidence obtained from randomized, controlled trials
Level B - recommendations are based on evidence obtained from controlled trials without randomization
Level C - recommendations are based on evidence obtained from cohort or case-control analytic studies and from multiple time series with or
without the intervention

Level D — recommendations are based on expert committee reports or opinions or clinical experience of respected authorities 


\section{Recommendations:}

1. If there are certain factors that increase the risk of scar dehiscence in pregnant women after a previous caesarean section, and in the case of an eventful obstetric history and failure to deliver vaginally, an elective caesarean section should be considered.

2. In the case of spontaneous initiation of labour in a pregnant woman after a previous caesarean section and in the absence of specific risk factors, patient consent for vaginal delivery is not required.

3. Labour after a previous caesarean section requires increased supervision of the pregnant woman due to the risk of uterine rupture in the post-caesarean scar.

4. During labour, continuous electronic monitoring of fetal heart activity is mandatory in pregnant women after a previous caesarean section.

5. Suspected uterine rupture after a previous caesarean section is an indication for immediate laparotomy.

6. Oxytocin can be used to support contractile function during labour in pregnant women after a previous caesarean section.

7. During vaginal delivery, epidural anaesthesia can be used in pregnant women after a previous caesarean section.

8. Labour pre-induction and induction can be performed in pregnant women after a previous caesarean section for maternal or fetal indications.

9. The use of prostaglandins is contraindicated in labour pre-induction and induction in pregnant women after a previous caesarean section.

10. There is no obligation to manually check the continuity of the scar after a vaginal delivery in women with a previous caesarean section.

\section{General recommendations for a caesarean section}

All pregnant women undergoing a caesarean section should be treated with antibiotics prior to the procedure. The recommended time of administration depends on the type of antibiotic. In the case of penicillins and cephalosporins, this should be between 30 and 10 minutes before the skin incision.

The uterine muscle should be incised transversely in the lower section, with its extension upwards on one or both sides. Under these conditions, the incision shape resembles the letter $U$ or part of it. In extreme situations, in the absence of the lower section development, classical incision of the uterine muscle should be considered.

Instrumental control of the uterine cavity after the placenta assessment is not obligatory.

The dilation of the cervical canal during caesarean section depends on the individual obstetric situation.

\section{Anticoagulant prophylaxis after a caesarean section}

Caesarean delivery may be associated with an increased risk of venous thromboembolism. In cases of elective caesarean section in women without additional risk factors, the right choice is hydration and early activation. Caesarean section for emergency indications, as well as the presence of risk factors (Tab. 2) is an indication for use of low molecular weight heparins after caesarean section.

\section{REFERENCES:}

1. World Health Organization Human Reproduction Programme, 10 April 2015. WHO Statement on caesarean section rates. Reprod Health Matters. $2015 ;$ 23(45): 149-150, doi: 10.1016/j.rhm.2015.07.007, indexed in Pubmed: 26278843.

2. Xie RH, Gaudet L, Krewski D, et al. Higher cesarean delivery rates are associated with higher infant mortality rates in industrialized countries. Birth. 2015; 42(1): 62-69, doi: 10.1111/birt.12153, indexed in Pubmed: 25597509.

3. https://prog.nfz.gov.pl/app-jgp/Start.aspx

4. Hannah ME, Hannah WJ, Hewson SA, et al. Planned caesarean section versus planned vaginal birth for breech presentation at term: a randomised multicentre trial. Term Breech Trial Collaborative Group. Lancet. 2000; 356(9239): 1375-1383, indexed in Pubmed: 11052579.

5. Crowther CA, Dodd JM, Hiller JE, et al. Birth After Caesarean Study Group. Planned vaginal birth or elective repeat caesarean: patient preference restricted cohort with nested randomised trial. PLoS Med. 2012; 9(3): e1001192, doi: 10.1371/journal.pmed.1001192, indexed in Pubmed: 22427749.

6. Spong $\mathrm{CY}$, Berghella $\mathrm{V}$, Wenstrom $\mathrm{KD}$, et al. Preventing the first cesarean delivery: summary of a joint Eunice Kennedy Shriver National Institute of Child Health and Human Development, Society for Maternal-Fetal Medicine, and American College of Obstetricians and Gynecologists Workshop. Obstet Gynecol. 2012; 120(5): 1181-1193, doi: http://10.1097/AOG.0b013e3182704880, indexed in Pubmed: 23090537.

7. Groen RS, Trelles M, Caluwaerts S, et al. A cross-sectional study of indications for cesarean deliveries in Médecins Sans Frontières facilities across 17 countries. Int J Gynaecol Obstet. 2015; 129(3): 231-235, doi: 10.1016/j. ijgo.2014.12.008, indexed in Pubmed: 25770352

8. Pallasmaa N, Ekblad U, Aitokallio-Tallberg A, et al. Cesarean delivery in Finland: maternal complications and obstetric risk factors. Acta Obstet Gynecol Scand. 2010; 89(7): 896-902, doi: 10.3109/00016349.2010.487893, indexed in Pubmed: 20583935.

9. Cantwell R, Clutton-Brock T, Cooper G, et al. Saving Mothers' Lives: Reviewing maternal deaths to make motherhood safer: 2006-2008. The Eighth Report of the Confidential Enquiries into Maternal Deaths in the United Kingdom. BJOG. 2011; 118 Suppl 1: 1-203, doi: 10.1111/j.1471-0 528.2010.02847.x, indexed in Pubmed: 21356004.

10. Creanga AA, Bateman BT, Butwick AJ, et al. Morbidity associated with cesarean delivery in the United States: is placenta accreta an increasingly important contributor? Am J Obstet Gynecol. 2015; 213(3): 384.e1384.11, doi: 10.1016/j.ajog.2015.05.002, indexed in Pubmed: 25957019.

11. Berthelot-Ricou A, Lacroze V, Courbiere B, et al. Respiratory distress syndrome after elective caesarean section in near term infants: a 5-year cohort study. J Matern Fetal Neonatal Med. 2013; 26(2): 176-182, doi: 10.3109/14767058.2012.733743, indexed in Pubmed: 23013109.

12. Jakobsson HE, Abrahamsson TR, Jenmalm MC, et al. Decreased gut microbiota diversity, delayed Bacteroidetes colonisation and reduced Th1 responses in infants delivered by caesarean section. Gut. 2014; 63(4): 559-566, doi: 10.1136/gutjnl-2012-303249, indexed in Pubmed: 23926244.

13. Sevelsted A, Stokholm J, Bønnelykke K, et al. Cesarean section and chronic immune disorders. Pediatrics. 2015; 135(1): e92-e98, doi: 10.1542/peds.2014-0596, indexed in Pubmed: 25452656.

14. Cardwell $C R$, Stene $L C$, Joner $G$, et al. Caesarean section is associated with an increased risk of childhood-onset type 1 diabetes mellitus: a meta-analysis of observational studies. Diabetologia. 2008; 51(5): 726735, doi: 10.1007/s00125-008-0941-z, indexed in Pubmed: 18292986. 
15. Zhang J, Troendle J, Mikolajczyk R, et al. The natural history of the normal first stage of labor. Obstet Gynecol. 2010; 115(4): 705-710, doi: 10.1097/AOG.0b013e3181d55925, indexed in Pubmed: 20308828.

16. Laughon SK, Branch DW, Beaver J, et al. Changes in labor patterns over 50 years. Am J Obstet Gynecol. 2012; 206(5): 419.e1-419.e9, doi: 10.1016/j. ajog.2012.03.003, indexed in Pubmed: 22542117.

17. Graseck A, Tuuli M, Roehl K, et al. Fetal descent in labor. Obstet Gynecol. 2014; 123(3): 521-526, doi: 10.1097/AOG.0000000000000131, indexed in Pubmed: 24499749.

18. Tuuli MG, Frey HA, Odibo AO, et al. Immediate compared with delayed pushing in the second stage of labor: a systematic review and meta-analysis. Obstet Gynecol. 2012; 120(3): 660-668, doi: 10.1097/AOG.0b013e3182639fae, indexed in Pubmed: 22872146.

19. Anim-Somuah $M$, Smyth R, Howell C. Epidural versus non-epidural or no analgesia in labour. Cochrane Database Syst Rev. 2005(4): CD000331, doi: 10.1002/14651858.CD000331.pub2, indexed in Pubmed: 16235275.

20. Wassen MM, Zuijlen J, Roumen FJ, et al. Early versus late epidural analgesia and risk of instrumental delivery in nulliparous women: a systematic review. BJOG. 2011; 118(6): 655-661, doi: 10.1111/j.1471-0528.2011.02 906.x, indexed in Pubmed: 21392241.

21. Harper LM, Caughey $A B$, Odibo $A O$, et al. Normal progress of induced labor. Obstet Gynecol. 2012; 119(6): 1113-1118, doi: 10.1097/AOG.0b013e318253d7aa, indexed in Pubmed: 22569121.

22. Rouse DJ, Weiner SJ, Bloom SL, et al. Eunice Kennedy Shriver National Institute of Child Health and Human Development (NICHD) Maternal-Fetal Medicine Units Network (MFMU). Failed labor induction: toward an objective diagnosis. Obstet Gynecol. 2011; $117(2$ Pt 1): 267-272, doi: 10.1097/AOG.0b013e318207887a, indexed in Pubmed: 21252738.

23. Simon CE, Grobman WA. When has an induction failed? Obstet Gynecol. 2005; 105(4): 705-709, doi: 10.1097/01.AOG.0000157437.10998.e7, indexed in Pubmed: 15802394.

24. Bomba-Opoń D, Drews K, Huras H, et al. Polish Gynecological Society Recommendations for Labor Induction. Ginekol Pol. 2017; 88(4): 224-234, doi: 10.5603/GP.a2017.0043, indexed in Pubmed: 28509326.

25. Stanowisko Ekspertów Polskiego Towarzystwa Ginekologicznego w zakresie zastosowania kardiotokografii w położnictwie. Ginekol Pol. 2014; 85: 713-716.

26. Neilson JP, Neilson JP, Neilson JP, et al. Fetal electrocardiogram plus heart rate recording for fetal monitoring during labour. Cochrane Database Syst Rev. 2000(2): CD000116, doi: 10.1002/14651858.CD000116, indexed in Pubmed: 10796139.

27. Rietberg CC, Elferink-Stinkens PM, Brand R, et al. Term breech presentation in The Netherlands from 1995 to 1999: mortality and morbidity in relation to the mode of delivery of 33824 infants. BJOG. 2003; 110(6): 604-609, indexed in Pubmed: 12798480.

28. Golfier F, Vaudoyer F, Ecochard R, et al. Planned vaginal delivery versus elective caesarean section in singleton term breech presentation: a study of 1116 cases. Eur J Obstet Gynecol Reprod Biol. 2001; 98(2): 186-192, indexed in Pubmed: 11574129.

29. Hofmeyr GJ, Hannah M, Lawrie TA. Planned caesarean section for term breech delivery. Cochrane Database Syst Rev. 2015(7): CD000166, doi: 10.1002/14651858.CD000166.pub2, indexed in Pubmed: 26196961.

30. Barrett JFR, Hannah ME, Hutton EK, et al. Twin Birth Study Collaborative Group. A randomized trial of planned cesarean or vaginal delivery for twin pregnancy. N Engl J Med. 2013; 369(14): 1295-1305, doi: 10.1056/NEJMoa1214939, indexed in Pubmed: 24088091.

31. Vogel JP, Holloway E, Cuesta C, et al. Outcomes of non-vertex second twins, following vertex vaginal delivery of first twin: a secondary analysis of the WHO Global Survey on maternal and perinatal health. BMC Pregnancy Childbirth. 2014; 14: 55, doi: 10.1186/1471-2393-14-55, indexed in Pubmed: 24484695.

32. Thomas PE, Petersen SG, Gibbons K. The influence of mode of birth on neonatal survival and maternal outcomes at extreme prematurity: A retrospective cohort study. Aust N Z J Obstet Gynaecol. 2016; 56(1): 60-68, doi: 10.1111/ajo.12404, indexed in Pubmed: 26391211.

33. Lannon SMR, Guthrie KA, Reed SD, et al. Mode of delivery at periviable gestational ages: impact on subsequent reproductive outcomes. J Perinat Med. 2013;41(6):691-697, doi: 10.1515/.jpm-2013-0023, indexed in Pubmed: 23924520.

34. Hofmeyr GJ, Kulier R. External cephalic version for breech presentation at term. Cochrane Database Syst Rev. 2000(2): CD000083, doi: 10.1002/14651858.CD000083, indexed in Pubmed: 10796122.

35. Hoffmann E, Oldenburg A, Rode L, et al. Twin births: cesarean section or vaginal delivery? Acta Obstet Gynecol Scand. 2012; 91(4):
463-469, doi: 10.1111/j.1600-0412.2011.01356.x, indexed in Pubmed: 22432546 .

36. Barrett JFR. Twin delivery: method, timing and conduct. Best Pract Res Clin Obstet Gynaecol. 2014; 28(2): 327-338, doi: 10.1016/j.bpobgyn.2013.12.008, indexed in Pubmed: 24445020.

37. Lees C, Marlow N, Arabin B, et al.TRUFFLE Group. Perinatal morbidity and mortality in early-onset fetal growth restriction: cohort outcomes of the trial of randomized umbilical and fetal flow in Europe (TRUFFLE). Ultrasound Obstet Gynecol. 2013; 42(4): 400-408, doi: 10.1002/uog.13190, indexed in Pubmed: 24078432

38. Figueras F, Gratacós E. Update on the diagnosis and classification of fetal growth restriction and proposal of a stage-based management protocol. Fetal Diagn Ther. 2014; 36(2): 86-98, doi: 10.1159/000357592, indexed in Pubmed: 24457811.

39. American College of Obstetricians and Gynecologists' Committee on Practice Bulletins-Obstetrics. Practice Bulletin No. 173: Fetal Macrosomia. Obstet Gynecol. 2016; 128(5): e195-e209, doi: 10.1097/AOG.0000000000001767, indexed in Pubmed: 27776071.

40. Burkhardt T, Schmidt M, Kurmanavicius J, et al. Evaluation of fetal anthropometric measures to predict the risk for shoulder dystocia. Ultrasound Obstet Gynecol. 2014;43(1): 77-82, doi: 10.1002/uog.12560, indexed in Pubmed: 23836579.

41. Conway DL, Langer O. Elective delivery of infants with macrosomia in diabetic women: reduced shoulder dystocia versus increased cesarean deliveries. Am J Obstet Gynecol. 1998; 178(5): 922-925, indexed in Pubmed: 9609560.

42. Anteby EY, Yagel S. Route of delivery of fetuses with structural anomalies. Eur J Obstet Gynecol Reprod Biol. 2003; 106(1): 5-9, indexed in Pubmed: 12475573.

43. Segel SY, Marder SJ, Parry S, et al. Fetal abdominal wall defects and mode of delivery: a systematic review. Obstet Gynecol. 2001; 98(5 Pt 1): 867-873, indexed in Pubmed: 11704185.

44. Wataganara $T$, Ngerncham $S$, Kitsommart $R$, et al. Fetal neck myofibroma J Med Assoc Thai. 2007; 90(2): 376-380, indexed in Pubmed: 17375646.

45. Alfirevic Z, Milan SJ, Livio S. Caesarean section versus vaginal delivery for preterm birth in singletons. Cochrane Database Syst Rev. 2012(6):CD000078, doi: 10.1002/14651858.CD000078.pub2, indexed in Pubmed: 22696314.

46. Lee HC, Gould JB. Survival rates and mode of delivery for vertex preterm neonates according to small- or appropriate-for-gestational-age status. Pediatrics. 2006; 118(6): e1836-e1844, doi: 10.1542/peds.2006-1327, indexed in Pubmed: 17142505.

47. Warke HS, Saraogi RM, Sanjanwalla SM. Should a preterm breech go for vaginal delivery or caesarean section. J Postgrad Med. 1999; 45(1): 1-4, indexed in Pubmed: 10734322.

48. JauniauxE, Ayres-de-Campos D. FIGO Placenta Accreta Diagnosis and Management Expert Consensus Panel. FIGO consensus guidelines on placenta accreta spectrum disorders: Introduction. Int J Gynaecol Obstet. 2018; 140(3): 261-264, doi: 10.1002/ijgo.12406, indexed in Pubmed: 29405322.

49. JauniauxE, Chantraine F, Silver RM, et al. FIGO Placenta Accreta Diagnosis and Management Expert Consensus Panel. FIGO consensus guidelines on placenta accreta spectrum disorders: Epidemiology. Int J Gynaecol Obstet. 2018; 140(3): 265-273, doi: 10.1002/ijgo.12407, indexed in Pubmed: 29405321.

50. Jauniaux E, Bhide A, Kennedy A, et al. FIGO Placenta Accreta Diagnosis and Management Expert Consensus Panel. FIGO consensus guidelines on placenta accreta spectrum disorders: Prenatal diagnosis and screening. Int J Gynaecol Obstet. 2018; 140(3): 274-280, doi: 10.1002/ijgo.12408, indexed in Pubmed: 29405319.

51. Silver RM, Barbour KD. Placenta accreta spectrum: accreta, increta, and percreta. Obstet Gynecol Clin North Am. 2015; 42(2): 381-402, doi: 10.1016/j.ogc.2015.01.014, indexed in Pubmed: 26002174.

52. Allen L, Jauniaux E, Hobson S, et al. FIGO Placenta Accreta Diagnosis and Management Expert Consensus Panel. FIGO consensus guidelines on placenta accreta spectrum disorders: Nonconservative surgical management. Int J Gynaecol Obstet. 2018; 140(3): 281-290, doi: 10.1002/ijgo.12409, indexed in Pubmed: 29405317.

53. Sentilhes L, Kayem G, Chandraharan E, et al. FIGO Placenta Accreta Diagnosis and Management Expert Consensus Panel. FIGO consensus guidelines on placenta accreta spectrum disorders: Conservative management. Int J Gynaecol Obstet. 2018; 140(3): 291-298, doi: 10.1002/ijgo.12410, indexed in Pubmed: 29405320.

54. Bręborowicz GH, Markwitz W, Gaca M, et al. Conservative management of placenta previa complicated by abnormal placentation. J Matern Fetal Neonatal Med. 2013; 26(10): 1012-1015, doi: 10.3109/14767058.2013.766708, indexed in Pubmed: 23350544. 
55. Jeejeebhoy FM, Zelop CM, Lipman S, et al. American Heart Association Emergency Cardiovascular Care Committee, Council on Cardiopulmonary, Critical Care, Perioperative and Resuscitation, Council on Cardiovascular Diseases in the Young, and Council on Clinical Cardiology. Cardiac Arrest in Pregnancy: A Scientific Statement From the American Heart Association. Circulation. 2015; 132(18): 1747-1773, doi: 10.1161/CIR.0000000000000300, indexed in Pubmed: 26443610.

56. James DK, Steer PJ, Weiner CP, et al. High Risk Pregnancy. Management Options. Saunders. 2011.

57. Jędrzejczak J, Bomba-Opoń D, Jakiel G, et al. Managing epilepsy in women of childbearing age - Polish Society of Epileptology and Polish Gynecological Society Guidelines. Ginekol Pol. 2017; 88(5): 278-284, doi: 10.5603/GP.a2017.0053, indexed in Pubmed: 28580576.

58. Konsensus okulistyczno-położniczy w sprawie wskazań do rozwiązania porodu drogą cięcia cesarskiego z powodu zmian w narządzie wzroku. https://www.ptgin.pl/index.php/lekarze/rekomendacje2/rekomendacje.

59. Holka-Pokorska J, Jarema M, Stefanowicz A, et al. Elective cesarean section on psychiatric indications - the phenomenon analysis, report of two cases and psychiatric clinical recommendations. Psychiatria Polska. 2016; 50(2): 357-373, doi: 10.12740/pp/43486.

60. Wielgoś M, Krzakowski M, Czajkowski K, et al. Standardy postępowania w przypadkach choroby nowotworowej u kobiety w ciąży Część I. Wiadomości ogólne: epidemiologia, diagnostyka, leczenie, poradnictwo genetyczne. Ginekologia i Perinatologia Praktyczna . 2016; 1(4): 172-188.

61. Wielgoś M, Krzakowski M, Czajkowski K, et al. Standardy postępowania w przypadkach choroby nowotworowej u kobiety w ciąży Część III. Rak piersi, raktarczycy. Ginekologia i Perinatologia Praktyczna. 2017;2(1):28-39.

62. Wielgoś M, Krzakowski M, Czajkowski K, et al. Standardy postępowania w przypadkach choroby nowotworowej u kobiety w ciąży Część II. Rak szyjki macicy, guzy jajnika. Ginekologia i Perinatologia Praktyczna. 2017; 2(1): 28-39.

63. Wielgoś M, Krzakowski M, Czajkowski K, et al. Standardy postępowania w przypadkach choroby nowotworowej u kobiety w ciąży Część IV. Nowotwory układu pokarmowego, rzadkie nowotwory . Ginekologia i Perinatologia Praktyczna . 2017; 2(2): 72-84.

64. Management of Genital Herpes in Pregnancy. RCOG BASHH. 2014.

65. British HIV Association guideline for the management of HIV infection in pregnant women 2012. HIV Medicine. 2014; 15: 1-77.

66. Grobman WA, Lai Y, Landon MB, et al. Eunice Kennedy Shriver National Institute of Child Health and Human Development Maternal-Fetal Medicine Units Network. Can a prediction model for vaginal birth after cesarean also predict the probability of morbidity related to a trial of labor? Am J Obstet Gynecol. 2009; 200(1): 56.e1-56.e6, doi: 10.1016/j. ajog.2008.06.039, indexed in Pubmed: 18822401.

67. Horenstein JM, Phelan JP. Previous cesarean section: the risks and benefits of oxytocin usage in a trial of labor. Am J Obstet Gynecol. 1985; 151(5): 564-569, indexed in Pubmed: 3976755.

68. Flamm BL, Goings JR, Fuelberth NJ, et al. Oxytocin during labor after previous cesarean section: results of a multicenter study. Obstet Gynecol. 1987; 70(5): 709-712, indexed in Pubmed: 3309751.

69. Bujold E, Blackwell SC, Gauthier RJ. Cervical ripening with transcervical foley catheter and the risk of uterine rupture. Obstet Gynecol. 2004 103(1): 18-23, doi: 10.1097/01.AOG.0000109148.23082.C1, indexed in Pubmed: 14704239.

70. Lydon-Rochelle M, Holt VL, Easterling TR, et al. Risk of uterine rupture during labor among women with a prior cesarean delivery. N Engl J Med. 2001;345(1):3-8, doi: 10.1056/NEJM200107053450101, indexed in Pubmed: 11439945. 